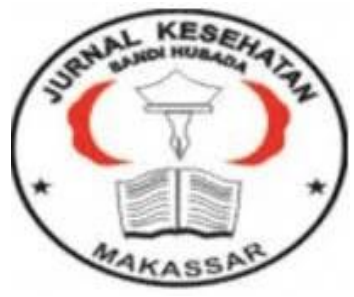

\author{
Jurnal Ilmiah Kesehatan Sandi Husada \\ hhttps://akper-sandikarsa.e-journal.id/JIKSH \\ Vol 9, No, 1, Juni 2020, pp; 18- 23 \\ p-ISSN: 2354-6093 dan e-ISSN: 2654-4563 \\ DOI: $10.35816 /$ jiskh.v10i2.210
}

\title{
Gambaran Efektivitas Penerapan Program Rehabilitasi Stroke Berbasis Rumah di Kota Makassar
}

Effectiveness of Implementation of House Based Stroke Rehabilitation Program in Makassar

\section{Yudi Hardianto', Rijal ${ }^{2}$, Fadhia Adliah ${ }^{3}$}

123Program Studi Fisioterapi, Fakultas Keperawatan Universitas Hasanuddin

\section{Artikel info}

Artikel history:

Received; 03 Februari 2020

Revised; 04 Februari 2020

Accepted; 06 Februari 2020

\begin{abstract}
This study aims to see a picture of the effectiveness of implementing a home-based stroke rehabilitation program. This research is a preliminary study involving 10 research subjects divided into 2 groups. Group 1 was given a rehabilitation program in the form of a physiotherapist's visit to provide exercise once a week. Group 2 was given 3 visits a week. A home-based stroke rehabilitation program in both groups was carried out for 1 month. In both groups, measurements of muscle strength, risk of falling and independence were measured. Each of the three variables was measured using a dynamometer, timed-up and go test, and functional independence measure (FIM). The results showed that group 2 had better muscle strength, risk of fall, and independence than group 1. This showed that in implementing a home-based stroke rehabilitation program, visits were more routine, at least 3 times a week, more recommended than visits that were only 1 time a week.
\end{abstract}

\begin{abstract}
Abstrak.
Penelitian ini bertujuan untuk melihat gambaran efektivitas penerapan program rehabilitasi stroke berbasis rumah. Penelitian ini merupakan penelitian pendahuluan dengan melibatkan 10 orang subjek penelitian yang dibagi menjadi 2 kelompok. Kelompok 1 diberikan program rehabilitasi berupa kunjungan fisioterapis untuk memberikan latihan selama 1 kali seminggu. Kelompok 2 diberikan kunjungan 3 kali seminggu. Program rehabilitasi stroke berbasis rumah pada kedua kelompok dilakukan selama 1 bulan. Pada kedua kelompok dilakukan pengukuran kekuatan otot, risiko jatuh dan kemandirian. Ketiga variabel tersebut masing-masing diukur dengan menggunakan dynamometer, timed-up and go test, dan functional independence measure (FIM). Hasil penelitian menunjukkan bahwa kelompok 2 memiliki kekuatan otot, risiko jatuh, dan kemandirian yang lebih baik dibanding kelompok 1. Hal ini menunjukkan bahwa dalam penerapan program rehabilitasi stroke berbasis rumah, kunjungan yang lebih rutin, paling tidak 3 kali seminggu, lebih disarankan dibanding kunjungan yang hanya 1 kali seminggu.
\end{abstract}

Yudi Hardianto, Rijal, Fadhia Adliah, Effectiveness of Implementation of House Based Stroke Rehabilitation Program in Makassar, JIKSH Vol 9 No 1 Juni 2020 
Keywords:

Stroke;

Program Rehabilitasi;
Coresponden author:

Email: yudihardianto@outlook.com

artikel dengan akses terbuka dibawah lisensi CC BY -4.0

\section{Pendahuluan}

Stroke merupakan salah satu penyakit yang paling sering menyebabkan ketergantungan dan penurunan kemampuan fungsional pada penderitanya. Menurut data Riset Kesehatan Dasar (Riskesdas) 2018, yang paling banyak menyebabkan ketergantungan berat dan ketergantungan total pada lansia dibanding penyakit-penyakit lainnya adalah penyakit stroke (Balitbang Depkes, 2018). Bahkan penderita stroke yang masuk kategori mandiri adalah yang paling sedikit dibanding penyakit-penyakit lainnya. Data Riskesdas 2018 juga menyebutkan bahwa angka kejadian stroke berdasarkan diagnosa dokter menunjukkan trend peningkatan dibanding data Riskesdas sebelumnya tahun 2013. Penanganan stroke yang komprehensif untuk meningkatkan kemandirian dan meminimalisir ketergantungan pasien stroke dapat dilakukan melalui program rehabilitasi (Winstein et al., 2016).

Di Indonesia, program rehabilitasi ini biasa dilakukan di rumah sakit atau klinik oleh fisioterapis dan profesi kesehatan lain yang tergabung dalam tim rehabilitasi. Layanan rehabilitasi di rumah sakit atau klinik tersebut biasanya berupa layanan rawat jalan, di mana penderita stroke harus datang ke rumah sakit atau klinik tiap hari atau beberapa kali seminggu. Hal tersebut terkadang tidak bisa dilakukan oleh pasien stroke, terutama yang mengalami ketergantungan berat hingga total. Berbagai faktor bisa menghalangi pasien stroke untuk mendapatkan program rehabilitasi di rumah sakit atau klinik. Di antaranya adalah tidak adanya keluarga yang mengantar, jarak yang jauh dari rumah sakit atau klinik, tidak memungkinkan untuk naik kendaraan umum, dan tidak sanggup harus mengantri lama di rumah sakit atau klinik. Dengan berbagai kendala tersebut, maka penderita stroke yang kemungkinan bisa berangsur-angsur pulih jika mendapatkan program rehabilitasi yang sesuai menjadi bertambah parah dan timbul komplikasi yang seharusnya bisa dihindari seperti nyeri dan kekakuan sendi (Lindgren et al., 2018), pola jalan yang salah (Neckel et al., 2008), gangguan postur (Persson et al., 2016) dan kelemahan kronik (Wu et al., 2015). Oleh karena itu, diperlukan suatu program yang bisa mengatasi kendala pasien stroke untuk mendapatkan rehabilitasi, yaitu dengan program rehabilitasi berbasis rumah.

Program rehabilitasi berbasis rumah adalah program rehabilitasi yang dilakukan di rumah pasien sendiri didampingi oleh keluarganya. Melalui program ini, bukan pasien yang harus berkunjung ke rumah sakit atau klinik, tetapi fisioterapis atau tim rehabilitasi yang mengunjungi pasien di rumahnya untuk memberikan rehabilitasi stroke berbasis rumah. Program rehabilitasi yang diberikan bertujuan untuk meningkatkan kemandirian pasien dan kemampuan fungsional dalam melakukan aktivitas-aktivitas dasar seperti makan, minum, berpakaian, buang air kecil, buang air besar, mandi, berjalan, dan naik tangga. Penelitian terkait efek rehabilitasi stroke berbasis rumah terhadap peningkatan kemampuan fungsional dan kemandirian penderita stroke telah dilakukan di beberapa negara, seperti Denmark (Rasmussen et al., 2016), Thailand (Chaiyawat \& Kulkantrakorn, 2012), dan Norwegia (Askim et al., 2010) dengan model rehabilitasi dan hasil yang bervariasi. Tujuan penelitian ini adalah untuk mengetahui gambaran program rehabilitasi berbasis rumah yang sesuai untuk diterapkan pada penderita stroke di Indonesia secara umum, dan di Kota Makassar secara khusus, dalam menurunkan tingkat ketergantungan penderita stroke dan meningkatkan kemampuan fungsional untuk melakukan aktifitas sehari-hari.

Yudi Hardianto, Rijal, Fadhia Adliah, Effectiveness of Implementation of House Based Stroke Rehabilitation Program in Makassar, JIKSH Vol 9 No 1 Juni 2020 


\section{Metode}

Penelitian ini adalah penelitian pendahuluan untuk melihat gambaran efektivitas penerapan program rehabilitasi stroke yang dilakukan di rumah pasien. Penelitian ini menggunakan metode pre and post, di mana dilakukan beberapa pengukuran seperti kekuatan otot, resiko jatuh, keseimbangan dan kemampuan fungsional sebelum dan sudah diberikan program rehabilitasi berbasis rumah pada pasien stroke. Lokasi penelitian adalah di Kota Makassar. Subjek penelitian terdiri atas 10 orang. Subjek dibagi menjadi 2 kelompok yang terdiri dari masing-masing 5 orang. Kelompok 1 diberikan program rehabilitasi dengan pendampingan 3 kali seminggu dan kelompok 2 diberikan program rehabilitasi berbasis rumah dengan pendampingan 1 kali seminggu. Kedua kelompok diberikan terapi selama 4 minggu berturut-turut. Pengukuran kemajuan subjek dilakukan sebelum diberikan program rehabilitasi, setelah 4 minggu pendampingan. Program rehabilitasi diberikan langsung oleh fisioterapis dengan didampingi oleh salah satu anggota keluarganya jika memungkinkan. Subjek dipandu untuk melakukan latihan sesuai dengan kebutuhannya dan fase kemampuannya. Media gambar-gambar latihan yang disertai instruksi tertulis diberikan kepada subjek untuk menjadi panduan ketika subjek melakukan latihan sendiri didampingi keluarga tanpa fisioterapis. Subjek diminta mengisi buku harian kegiatan sehari-hari dan program latihan yang dijalaninya. Analisis data penelitian dilakukan secara kuantitatif dengan menggunakan SPSS. Data kuantitatif ditampilkan secara deskriptif dan inferensial untuk melihat perubahan penderita stroke setelah diberikan program rehabilitasi dan perbandingan perubahan tersebut antara kedua kelompok. Sebelum dilakukan uji statistik pada data penelitian yang telah dikumpulkan, terlebih dahulu dilakukan uji normalitas. Data yang berdistribusi normal diuji dengan menggunakan uji parametrik, sedangkan data yang tidak berdistribusi normal diuji dengan menggunakan uji non parametrik. Hasil dari uji statistik baik parametrik maupun non parametrik dikatakan signifikan apabila didapatkan nilai $\mathrm{p}<0,05$.

\section{Hasil Dan Pembahasan}

Karakteristik subjek penelitian ditampilkan di Tabel 1. Hasil penelitian menunjukkan bahwa antara kedua kelompok tidak memiliki perbedaan yang signifikan ditinjau dari usia, jenis kelamin, dan lama stroke.

Tabel 1 Karakteristik Subjek Penelitian

\begin{tabular}{|c|c|c|c|c|}
\hline & Kelompok 1 & \multicolumn{3}{|c|}{ Kelompok 2} \\
\hline Usia, rata-rata & 60.88 & \multicolumn{2}{|c|}{60.73} & \\
\hline Jenis Kelamin (Perempuan) & $60 \%$ & \multicolumn{2}{|c|}{$63 \%$} & \\
\hline Lama stroke & $<1$ tahun & \multicolumn{2}{|c|}{$<1$ tahun } & \\
\hline \multicolumn{5}{|c|}{$\begin{array}{l}\text { Hasil pengukuran kekuatan otot, risiko jatuh, dan kemandirian subjek penelitian ditampilkan d } \\
\text { Tabel 2. Hasil pengukuran kekuatan otot menunjukkan bahwa sebelum diberikan program latihar } \\
\text { pada kedua kelompok, nilai kekuatan otot tungkai tidak berbeda secara signifikan antara kelompol } \\
\text { Tabel } 2 \text { Hasil pengukuran kekuatan otot, risiko jatuh, dan kemandirian }\end{array}$} \\
\hline Variabel & Pengukuran & Kelompok 1 & Kelompok 2 & $\mathrm{P}$ \\
\hline \multirow[t]{3}{*}{ Kekuatan Otot (Dynamometer) } & Pre & 10.22 & 9.87 & $\mathrm{P}>0.05$ \\
\hline & Post & 13.44 & 15.78 & $\mathrm{P}<0.05$ \\
\hline & \multicolumn{4}{|c|}{$\mathrm{P}<0.05$} \\
\hline \multirow[t]{3}{*}{ Risko Jatuh (TUG) } & Pre & 22.34 & 21.54 & $\mathrm{P}>0.05$ \\
\hline & Post & 20.56 & 18.34 & $\mathrm{P}<0.05$ \\
\hline & \multicolumn{4}{|c|}{$\mathrm{P}<0.05$} \\
\hline \multirow[t]{2}{*}{ Kemandirian (FIM) } & Pre & 89.55 & 87.43 & $\mathrm{P}>0.05$ \\
\hline & Post & 105.43 & 111.23 & $\mathrm{P}<0.05$ \\
\hline
\end{tabular}

Yudi Hardianto, Rijal, Fadhia Adliah, Effectiveness of Implementation of House Based Stroke Rehabilitation Program in Makassar, JIKSH Vol 9 No 1 Juni 2020 
Hasil penelitian ini menunjukkan bahwa sebelum diberikan program rehabilitasi stroke berbasis rumah, kedua kelompok tidak memiliki perbedaan yang signifikan dalam hal kekuatan otot, risiko jatuh, dan kemandirian dalam melakukan ADL. Setelah diberikan program rehabilitasi stroke berbasis rumah, baik kelompok perlakuan maupun kelompok kontrol mengalami peningkatan kekuatan otot, penurunan risiko jatuh dan perbaikan kemandirian melakukan ADL secara signifikan. Ketika dibandingkan antara kedua kelompok, terdapat perbedaan yang signifikan, di mana kelompok perlakuan mengalami peningkatan kekuatan otot, penurunan risiko jatuh, dan perbaikan kemandirian ADL, lebih baik dibandingkan kelompok kontrol.

Sebuah review dari Mayo (2016) menunjukkan bahwa pasien stroke yang dirawat di rumah tanpa mendapatkan program rehabilitasi berbasis rumah memiliki risiko ketergantungan dan kematian yang lebih tinggi dibanding pasien stroke yang mendapatkan program rehabilitasi berbasis rumah dalam bentuk early supported discharge, terutama ketika diberikan oleh tim multidisiplin. Hal ini menunjukkan bahwa program rehabilitasi berbasis rumah sangat penting perannya dalam meningkatkan kemandirian pasien dalam melakukan aktivitas sehari-hari dan mengurangi risiko ketergantungan pasien terhadap orang lain dalam beraktivitas. Selain itu, penurunan aktivitas pada penderita stroke dapat meningkatkan risiko kematian.

Penelitian yang dilakukan oleh Berg et al. (2016) di Adelaide, Australia menunjukkan bahwa rehabilitasi berbasis rumah yang dibantu oleh keluarga atau orang yang merawat pasien memiliki efek yang signifikan terhadap kualitas hidup pasien stroke. Hasil yang sama juga didapatkan pada penelitian Vloothuis et al. (2019) yang dilakukan di Amsterdam, Belanda secara paralel dengan protokol penelitian yang sama. Pada penelitian tersebut didapatkan bahwa selain tidak memiliki hasil yang berbeda dengan program rehabilitasi standar, program rehabilitasi berbasis rumah justru lebih baik dalam mengatasi kecemasan pasien stroke dan depresi pada keluarga dekat yang merawat pasien. Pada penelitian kami, sebagian subjek penelitian melakukan latihan yang dibantu oleh pasangan atau anggota keluarganya yang lain. Hal ini dimaksudkan agar pasien lebih nyaman ketika diberikan support oleh anggota keluarganya sendiri. Diharapkan juga motivasi pasien meningkat ketika dilatih oleh orang-orang terdekatnya. Selain itu, rehabilitasi berbasis rumah yang difasilitasi oleh anggota keluarga pasien lebih hemat biaya dan memungkinkan untuk dilakukan melalui supervisi dari fisioterapis atau tim rehabilitasi terhadap anggota keluarga pasien tersebut.

Penelitian rehabilitasi stroke berbasis rumah juga sudah pernah dilakukan di Surabaya, Indonesia oleh Widarti and Krisnawati (2017). Pada penelitian tersebut, pasien stroke diberikan intervensi keperawatan untuk memastikan segala kebutuhan pasien stroke terkontrol dan terpenuhi. Pasien diberikan kunjungan rutin selama tiga bulan. Hasilnya menunjukkan bahwa intervensi yang diberikan berupa home care tersebut mampu mengurangi tingkat kecemasan dan depresi pada pasien stroke. Pada penelitian kami, sebagian pasien stroke yang dijadikan subjek penelitian menunjukkan tanda kecemasan, namun hal tidak diidentifikasi lebih lanjut apakah kecemasan tersebut adalah kecemasan ringan atau kecemasan yang mengarah ke depresi. Kecemasan dan depresi pada pasien stroke merupakan hal yang umum terjadi, karena belum bisa menerima perubahan kondisinya secara penuh dan memikirkan hal-hal lain yang membuat pasien merasa tertekan dan tak berdaya. Program rehabilitasi berbasis rumah diharapkan dapat meringankan kecemasan dan depresi pasien tersebut dengan melibatkan orang-orang terdekat pasien. Pemahaman orang-orang terdekat pasien terkait kondisi fisik dan mental pasien stroke sangat penting bagi prognosis pasien stroke ke depannya. Pasien stroke yang lingkungan sekitarnya suportif dengan keadaannya akan lebih baik perkembangannya dibanding pasien stroke yang orang-orang sekitarnya tidak suportif. Melalui program rehabilitasi stroke berbasis rumah diharapkan selain penganganan yang diberikan kepada pasien stroke sendiri, edukasi juga diberikan kepada orang-orang di sekitar pasien stroke terkait kondisi stroke secara umum, sehingga memberikan pemahaman yang komprehensif bagi mereka bagaimana berinteraksi dengan pasien stroke.

Sebagai penelitian pendahuluan, penelitian ini tentu memiliki beberapa keterbatasan untuk bisa digeneralisir hasilnya ke penderita stroke secara umum. Dari segi jumlah subjek penelitian, 
penelitian ini hanya melibatkan 10 orang subjek penelitian, sehingga secara kekuatan statistik masih sangat kurang. Blinding subjek penelitian tidak memungkinkan untuk dilakukan dalam penelitian ini, karena subjek penelitian menyadari bahwa mereka berada di kelompok 1 atau kelompok 2. Namun demikian, alat ukur yang digunakan dalam penelitian ini tidak berdasarkan patient-reported outcome, sehingga dianggap blinding subjek tidak mempengaruhi hasil pengukuran. Keterbatasan lainnya adalah tidak adanya perbandingan dengan pasien stroke yang menjalani rehabilitasi stroke standar sebagai kelompok kontrol.

\section{Simpulan Dan Saran}

Dari hasil penelitian ini, dapat disimpulkan bahwa program rehabilitasi berbasis rumah yang diberikan 3 kali seminggu memberikan dampak efek yang signifikan bagi penderita stroke yang dirawat di rumah. Berdasarkan hasil penelitian ini, maka peneliti menyarankan penerapan program rehabilitasi stroke berbasis rumah dilanjutkan ke penelitian yang lebih besar dengan jumlah subjek penelitian yang lebih banyak untuk melihat bagaimana efektivitas dan efisiensi program rehabilitasi stroke berbasis rumah terhadap pasien. Hal ini akan menjadi dasar penerapan program rehabilitasi stroke berbasis rumah untuk membantu pasien stroke yang membutuhkan layanan rehabilitasi intensif yang sulit mereka dapatkan ketika harus ke rumah sakit atau klinik.

\section{Ucapan Terima Kasih}

Ucapan terima kasih kami haturkan kepada Lembaga Penelitian dan Pengabdian kepada Masyarakat Universitas Hasanuddin yang telah membiayai penelitian ini melalui skema hibah Penelitian Dosen Pemula Unhas. Ucapan terima kasih juga untuk semua pihak yang telah membantu terlaksananya penelitian ini yang tidak bisa disebutkan satu per satu.

\section{Daftar Rujukan}

Askim, T., Mørkved, S., Engen, A., Roos, K., Aas, T., \& Indredavik, B. (2010). Effects of a CommunityBased Intensive Motor Training Program Combined With Early Supported Discharge After Treatment in a Comprehensive Stroke Unit. Stroke, 41(8), 1697-1703. doi:doi:10.1161/STROKEAHA.110.584284

Balitbang Depkes, R. (2018). Riskesdas 2018. In: Jakarta.

Berg, M. v. d., Crotty, M., Liu, E., Killington, M., Kwakkel, G., \& Wegen, E. v. (2016). Early Supported Discharge by Caregiver-Mediated Exercises and e-Health Support After Stroke. Stroke, 47(7), 1885-1892. doi:doi:10.1161/STROKEAHA.116.013431

Chaiyawat, P., \& Kulkantrakorn, K. (2012). Effectiveness of home rehabilitation program for ischemic stroke upon disability and quality of life: a randomized controlled trial. Clinical neurology and neurosurgery, 114(7), 866-870.

Lindgren, I., Gard, G., \& Brogårdh, C. (2018). Shoulder pain after stroke-experiences, consequences in daily life and effects of interventions: a qualitative study. Disability and rehabilitation, 40(10), 1176-1182.

Mayo, N. E. (2016). Stroke Rehabilitation at Home. Stroke, 47(6), 1685-1691. doi:doi:10.1161/STROKEAHA.116.011309

Neckel, N. D., Blonien, N., Nichols, D., \& Hidler, J. (2008). Abnormal joint torque patterns exhibited by chronic stroke subjects while walking with a prescribed physiological gait pattern. Journal of neuroengineering and rehabilitation, 5(1), 19.

Persson, C. U., Hansson, P.-O., Lappas, G., \& Danielsson, A. (2016). Physical activity levels and their associations with postural control in the first year after stroke. Physical therapy, 96(9), 1389-1396. 
Rasmussen, R. S., Østergaard, A., Kjær, P., Skerris, A., Skou, C., Christoffersen, J., . . Overgaard, K. (2016). Stroke rehabilitation at home before and after discharge reduced disability and improved quality of life: A randomised controlled trial. Clinical rehabilitation, 30(3), 225 236.

Vloothuis, J. D., Mulder, M., Nijland, R. H., Goedhart, Q. S., Konijnenbelt, M., Mulder, H., . . Kwakkel, G. (2019). Caregiver-mediated exercises with e-health support for early supported discharge after stroke (CARE4STROKE): A randomized controlled trial. PLoS One, 14(4).

Widarti, L., \& Krisnawati, K. (2017). Home Care Holistic on the Change of Anxiety and Depression for the Patient with Stroke Ischemic. Jurnal Ners, 7(2), 107-115.

Winstein, C. J., Stein, J., Arena, R., Bates, B., Cherney, L. R., Cramer, S. C., . . Harvey, R. L. (2016). Guidelines for adult stroke rehabilitation and recovery: a guideline for healthcare professionals from the American Heart Association/American Stroke Association. Stroke, 47(6), e98-e169.

Wu, S., Mead, G., Macleod, M., \& Chalder, T. (2015). Model of understanding fatigue after stroke. Stroke, 46(3), 893-898. 